\title{
RUÍNA IDENTITÁRIA EM A CÉU ABERTO, DE JOÃO GILBERTO NOLL
}

\author{
Ana Carla da Silva Lima \\ Mestranda em Estudos Literários pela Universidade Estadual de Londrina (UEL) \\ anacsslima@gmail.com
}

\section{RESUMO}

Considerando a problematização constante acerca da identidade contemporânea, este trabalho tem como objetivo realizar uma análise-intepretativa com foco na construção identitária do protagonista de A céu aberto (1996), de João Gilberto Noll. Para tanto, utilizamos como subsídio teórico a fortuna crítica já existente sobre o autor e sobre a obra, como Treece (1997), Pinto (2004), Schollhammer (2009) e Hartmann (2011), bem como estudiosos que teorizaram sobre a fragmentação da identidade contemporânea e suas relações com a sociedade, como Bauman (2005) e Hall (2006).

Palavras-chave: Identidade, João Gilberto Noll, A céu aberto.

\begin{abstract}
Considering the constant problematization about the contemporary identity, this paper aims to realize an interpretative analysis focusing on the identity construction of the protagonist of $A$ céu aberto (1996), by João Gilberto Noll. We use as theoretical foundation the already existing bibliography about Noll's literature, as Treece (1997), Pinto (2004), Schollhammer (2009) and Hartmann (2011), as well as scholars that theorize about the fragmentation of the contemporary identity and its relations with society, as Bauman (2005) and Hall (2006).
\end{abstract}

Keywords: Identity, João Gilberto Noll, A céu aberto. 
"Jamais se ganha batalha alguma, ele disse. Nenhuma batalha sequer é lutada. O campo revela ao homem apenas sua própria loucura e desespero."

(William Faulkner)

\section{De ruínas e entranhas: a literatura de João Gilberto Noll}

A expressividade de João Gilberto Noll não demorou a se firmar no cenário da literatura brasileira contemporânea. Em meados da década de oitenta, a publicação do volume de contos $O$ cego e a dançarina (1980) Ihe rendeu três prêmios: "Revelação do Ano", da Associação Paulista de Críticos de Arte; "Ficção do Ano", do Instituto Nacional do Livro e o "Prêmio Jabuti" na categoria de autor revelação. Ao longo de sua vida, o escritor gaúcho publicou 19 obras, incluindo romances, contos e micronarrativas, tendo conquistado o "Prêmio Jabuti" em cinco ocasiões, além de adaptações para o cinema de algumas de suas obras.

De acordo com Manoel da Costa Pinto (2004), a literatura brasileira contemporânea, em especial a prosa, se volta para o urbano como um reflexo da vida nas grandes cidades. A indefinição ronda os estilos, enquanto a linguagem percorre "ruas deterioradas, botecos esquálidos, casas traumatizadas pelo desemprego, pela violência e pela loucura -, há uma percepção geral do isolamento e da vulnerabilidade do sujeito moderno (e urbano)" (PINTO, 2004, p. 82). O crítico ainda aponta para o aspecto nômade dos textos de Noll, pois "em todos eles, permanece como experiência de fundo o desenraizamento" (PINTO, 2004, p. 82).

Em sua produção romanesca, o nomadismo e a desterritorialização constroem a condição de seus personagens-narradores que parecem compor um único ser de trânsito ininterrupto. Sobre essa constante no universo de Noll, Hartmann (2011) sugere o germe 
da voz narrativa nolleana: "andarilho propenso à caminhada, desse ir e vir que nunca cessa" (HARTMANN, 2011, p. 23). Dessa forma, é possível pensarmos na continuidade e adaptação desse sujeito, conforme a sua caminhada progride. Faz, assim, apresentar uma literatura que transita junto ao sujeito e aponta para a construção de um universo que é inscrito em uma linguagem única, transpondo a urgência de estar sempre em movimento.

Ao pensarmos na literatura de João Gilberto Noll como um todo, em um primeiro momento é possível perceber algumas constâncias: os narradores são sempre avulsos de vozes incógnitas, que percorrem a esmo caminhos que não são trilhas, mas passos largos, que não resvalam em pontos de referências, e tomam como bússola o imediatismo dos acontecimentos exteriores, deixando lacunas maiores do que os fragmentos que foram expostos.

Para Manoel da Costa Pinto (2003), seriam "romances de deformação". O que muda o tom de cada romance é o que move a escrita, seja a identidade, a libido ou a travessia, todas intensificadas ao extremo e proporcionando experiências múltiplas. Assim, os narradores - que são apenas um - são flexíveis e plurais, a ponto de explorarem todos os elementos que percorrem as questões de um sujeito pós-moderno. Desse desdobramento, Hartmann afirma que as características fundamentais da literatura de Noll vão,

em múltiplas facetas, do minimalismo cotidiano à negação da subjetividade, do não enquadramento ao tradicional ao romance deformidade, das peripécias do corpo a uma sexualidade lasciva e sacralizada, todos são elementos que estruturam o pano de fundo incorporado às realidades ficcionais de João Gilberto Noll (HARTMANN, 2011, p. 24). 
O termo que Bauman (2005) utiliza é o de "modernidade líquida", em que se acolhe a transitoriedade de todos os alicerces culturais, sociais e históricos. Esse processo, segundo o autor, desestabilizou as subjetividades. Nesse sentido, as narrativas de Noll percorrem esse caminho instável: o simulacro expõe a busca impossível e a adaptação quase-que-instantânea.

Podemos, ainda, relacionar a esse caos externo e interno o que Stuart Hall (2006) aponta sobre a identidade pós-moderna:

As velhas identidades, que por tanto tempo estabilizaram o mundo social, estão em declínio, fazendo surgir novas identidades e fragmentando o indivíduo moderno, até aqui visto como um sujeito unificado. A assim chamada 'crise de identidade' é vista como parte de um processo mais amplo de mudança, que está deslocando as estruturas e processos centrais das sociedades modernas e abalando os quadros de referência que davam aos indivíduos uma ancoragem estável no mundo social (HALL, 2006, p. 7).

João Gilberto Noll é considerado um dos representantes pós-modernos da literatura brasileira contemporânea, segundo Karl Erik Schollhammer (2009). O crítico ainda afirma que, desde o romance $A$ fúria do corpo (1981) até a publicação de $A$ céu aberto (1991), "Noll cumpre uma trajetória que o identifica, inicialmente, como o intérprete mais original do sentimento pós-moderno de perda de sentido e de referência" (SCHOLLHAMMER, 2009, p. 32). O autor prossegue:

Sua narrativa se move sem um centro, não ancorada num narrador autoconsciente; seus personagens se encontram em processo de esvaziamento de projetos e de personalidade, em crise de identidade nacional, social e sexual, mas sempre à deriva e à procura de pequenas e perversas realizações do desejo. Acontecimentos violentos interrompem seus trajetos de modo enigmático e deixam o corpo em estado de ferida e num arriscado percurso de vulnerabilidade e exposição. Sempre em 
movimento, perambulando numa geografia incerta, o movimento narrativo de Noll é a viagem obtusa em que fronteiras são abolidas, e dimensões temporais e espaciais são questionadas por trajetos errantes que cruzam um território sem claras definições, produzindo um movimento hesitante em direção a Porto Alegre, a cidade que, do romance Hotel Atlântico a Lorde, simboliza a origem, o lar e a identidade que nunca são retomados (SCHOLLHAMMER, 2009, p. 32).

A partir dos pormenores explicitados pelos autores já citados, é possível depreender que as narrativas do Noll permitem um diálogo entre elas e, também, uma interpretação desse personagem/narrador como aquele que se desloca, provocando essa sintonia entre os espaços e entre as representações do homem imerso num universo contemporâneo que dificulta o desenho de limites e contornos. Cabem aqui alguns dos conceitos radicalmente explorados por Noll, como a linguagem, a identidade, a subjetividade, o deslocamento, a sexualidade, a memória e a melancolia de ser humano. É a partir dessas circunstâncias que, no prefácio de Romances e contos reunidos, David Treece (1997) crava a seguinte assertiva,

Numa virada de século em que já se anunciou que não há mais histórias por fazer, em que as opções teriam sido reduzidas a uma única ordem globalizante, em que apenas resta nos rendermos como consumidores diante do mercado de bens físicos e simbólicos à venda, destaca-se no meio da conformidade uma voz disposta a enunciar um sentimento de insuficiência diante do real, a certeza de que a potencialidade humana está travada e de que seus desdobramentos possíveis não foram esgotados, é ali, então, não num voluntarismo facilmente idealista ou utópico, mas na zona crítica entre a recusa da realidade assim como é o prenuncio do possível, que se dá o drama humano e artístico da fiç̧ão de Noll (TREECE, 1997, p. 7).

O drama humano dos protagonistas nolleanos é experimentado numa encruzilhada entre o abismo de ser e existir para com o mundo e nas possibilidades de 
pertencer ao ordinário. Isso fica mais claro na necessidade compulsiva de se deslocar que o protagonista de Harmada (1993) tem; conforme ele esbarra em possíveis laços permanentes nas suas relações, o impulso de transitar surge e a narrativa o segue em rumos aleatórios. Apesar de seus personagens representarem uma espécie de anonimato do mundo pós-moderno, eles também demonstram, de certa forma, movimentos que se tornam universais, como a destruição de certezas. Aqui, por exemplo, cabe-nos pensar na metáfora apresentada em epígrafe, retirada dos versos que compõem o poema The waste land, escrito por T. S. Eliot, com publicação datada de 1956: são fragmentos escorados em ruínas que constituem o corpo e a identidade dos homens - o que transparece no incompleto e inacabado de Noll - que entram em consonância com os principais aspectos do contemporâneo guiados pela instabilidade constante.

Considerando as exposições até aqui feitas, este trabalho se constitui como uma tentativa de interpretar a construção de identidade do protagonista do romance A céu aberto, de 1996.

\section{Em fragmentos: um sujeito errante}

O início da narrativa se dá em memórias incertas, com lembranças do seu tempo de escola, o que ocorre em meio a um pesadelo, inflando o sintoma de que o passado o transtorna tanto quanto o presente. Justo no começo do romance, uma marca dessa incerteza temporal aparece: "Sacudi o meu irmão na cama ao lado e perguntei se ele ouvira as badaladas do sino ao meio-dia... ao meio-dia de ontem ou de hoje?, eu mesmo perguntei distraído" (NOLL, 1996, p. 10). A experiência da dúvida absoluta possibilita interpretações no sentido de que o tempo lhe é indiferente (no que tange a sua passagem 
de passado para presente), ou não lhe é apreensível. Tais possibilidades acabam refletindo o quão avulsa a sua identidade é.

Em um primeiro momento, o que gera a perambulação do narrador é a sua relação com seu irmão. Sozinhos, o narrador se responsabiliza pela saúde fragilizada de seu irmão mais novo. A situação de abandono em que ambos se encontram faz com que o narrador deposite sua força de busca em seu irmão:

eu precisava fazer alguma coisa pela saúde meu irmão [...] eu estou é te olhando como irmão mais velho que sou, e você continuará sendo o meu pirralho de sempre, e repito que devemos procurar o nosso pai que está na guerra, e que estará na guerra até o fim pelo pouco que conheço dele (NOLL, 1996, p. 12).

O empenho em ajudar o irmão demanda que essa busca seja colocada na estrada. Esse depósito de forças em outro ser humano pode ser metáfora também para o laço firme que a relação representa. Afinal, a maioria dos narradores de Noll não possuem relações duradouras que envolvam comprometimento. Dessa forma, podemos pensar nessa relação ou nesse comprometimento como uma maneira de manter-se fixo a si mesmo, para que o eu não lhe escape: "eu daí virava as costas e ia à procura do meu irmão para me garantir uma vida fora do espelho" (NOLL, 1994, p. 66).

Prevendo o efeito da peregrinação, o narrador lhe pede que observe o que ainda se encontra diante do espelho, destacando e alertando o impasse da identidade. É possível a interpretação de que não se trata apenas do abandono do pai em relação a eles, mas também do abandono de suas próprias identidades.

Ajudei-o então a se levantar e o meti na frente de uma lasca de espelho que mantínhamos entre nossas camas. Falei: te olha bem, depois você 
sabe que não encontrará outro espelho por muito tempo, no caminho só uma ou outra superfície de algum lago quem sabe um rio, no campo de batalha não há espelhos, salvo talvez para os generais espelhos miúdos escondidos dentro da tenda do acampamento de guerra, talvez embaixo da cama (NOLL, 1996, p. 13).

A imposição de algumas resoluções ou interpretações se dificultam à medida que as afirmações na narrativa do Noll se atropelam; existem contradições e confusões do narrador com a realidade, e a menção ao espelho pode ser interpretada como uma tentativa de reconhecer-se ou de encontrar um reflexo de si mesmo no irmão. Em seguida, saem os dois em busca do pai no campo de batalha.

\footnotetext{
Não, eu não estava doente como o meu irmão, eu não precisaria de nada; até se a coisa ficasse ainda mais feia não sei de que jeito, mesmo se eu tivesse vamos dizer de tocar na goela hirta do horror, mesmo assim eu sobreviveria a tudo pensava eu - já ele não, ele precisava em quantas ocasiões da força dos meus braços para mantê-lo com a espinha ereta e da destreza das minhas mãos para mantê-lo limpo (NOLL, 1994, p. 18).
}

O protagonista se coloca à disposição das necessidades de seu irmão; mesmo consciente de seus limites, prossegue, como consta no excerto acima, quando ele menciona partes de seu corpo e a busca pelo pai serve de objetivo estável em contraponto à instabilidade que o compõe. Essa relação do corpo com a identidade também é bastante explorada por alguns críticos, a depender da tônica de cada romance. Em A céu aberto, a experiência identitária se faz mais pertinente, visto que a constituição do enredo se dá em travessias e estilhaços - entre memórias e relações à deriva.

A partir dessa contemplação, a narrativa fica confusa na medida em que Artur é introduzido. Com ele, a narrativa promove analepses entre o campo e os episódios filosóficos e contemplativos. 
Artur surge como um pianista, amigo do pai. Em uma noite em que o pai dos dois meninos já estava em guerra, o músico convida o protagonista para assistir a ele. Os dois passam a morar juntos, e Artur acaba assumindo uma representação totalmente contrária ao pai militar do protagonista. As descrições feitas pelo narrador nos levam a interpretar que a figura Artur era consideravelmente mais velho que o protagonista, pois, nas palavras dele se tratava de "um velho pederasta". Enquanto o irmão continua em uma espécie de limbo, a relação do protagonista com Artur perdura.

A estrutura narrativa evolui em fluidez, e as marcas de espaço e de tempo se tornam mais fragmentadas, até Artur ser diluído por entre o enredo. De volta ao campo, o protagonista reflete sobre o que lhe está sendo exposto: a guerra, mas que podemos tomar como uma analogia para a conjuntura panorâmica do sujeito.

[...] só sei que vivíamos ali eu e o soldado franzino uma situação onde os motivos estavam anulados em nome da guerra, que coisas como mentir perdoar gritar chorar ou revolver o pensamento só podiam existir mesmo numa cabeça alienígena do exército como a minha (NOLL, 1994, p. 42).

Os devaneios o levam à sensação de pertencimento, resolvendo seus "problemas de existência", caso fizesse parte do exército. A projeção que o protagonista faz, ao se incluir no grupo, segue uma lógica que ele, aparentemente, acha patética:

[...] vi que agora eu deveria segui-lo até o almoço, quem sabe reencontrar meu pai, saber da saúde do meu irmão, seguir a vida com rédeas curtas de sempre, não alterar plano algum, morrer no fim do dia, alguma coisa assim... (NOLL, 1996, p. 44). 
Do patético ao apático, o narrador, ao mesmo tempo em que recua por conformismo frente ao real insatisfatório, segue a esmo. Em conversa com outro sentinela, o narrador escuta como o outro rapaz foi convocado para o campo de batalha daquela guerra. Revivendo a memória de humilhação e dor alheia, dispara: “[...] eu quero é voltar para o lugar de onde nunca deveria ter saído, eu quero é me apagar" (NOLL, 1996, p. 49). Em seguida, o protagonista é abusado sexualmente por seu general, mas não pestaneja, segue resignado àquilo. Os sinais de aceitação da realidade são percebidos em detalhes por falta de revolta e, principalmente, por se considerar impotente no sentido de existir, de pertencer e permanecer em seu posto, dadas as ponderações feitas até então. O seguinte excerto do romance deixa claro esse processo de diluição e apatia que o protagonista elabora por si mesmo, evidenciando-se também a consciência de uma biografia desabitada.

Fugi da sombra. Sentei-me no chão. O sol agora quase a pino fazia de mim uma silhueta adelgaçada na terra vermelha. A cada lenta colherada eu percebia no solo a minha imagem como se tivesse tromba, e tudo era tão casual na minha maneira de estar comendo sem muito gosto naquele acampamento militar, que me deu vontade de pertencer a uma ordem precisa como a daquele exército debaixo daquele sol com uma galáxia de homens coesa, ali mesmo sim e não em outro mundo, um corpo de guerreiros ao qual eu poderia tentar pertencer. Exigiriam algum suplício para que eu pudesse entrar em suas fileiras? De graça, assim, sem dar provas da minha valentia eles me aceitariam como um dos seus?

Não, pois eu era um homem só e como tal deveria seguir - esta ideia me bateu como um choque na cabeça. Que exército iria querer incluir em suas fileiras um homem que nem eu?, alguém que não sabia bem a idade e que dava atenção a poucas coisas além do encaminhamento do irmão, que no mais ficava à toa, sem planos para o futuro, às vezes com acentuada amnésia, em certas ocasiões com vontade de morrer, em outras com uma alegria tão insana a ponto de chorar de dor, então... sendo um homem escandalosamente desimpedido das urgências do mundo, quem iria me convocar para a guerra onde cada um deve 
dissolver seu andamento próprio em nome da faina de vencer... e a indagação mais grave: que mulher, que filhos, que grandes amigos eu deixaria no cotidiano normal a sofrer a minha falta ou a dourar minha imagem acomodando na memória a vaga urna de um herói... quem me convocaria com uma biografia assim... heim? (NOLL, 1996, p. 50-51)

Como indicado no começo deste trabalho, o peso de seu irmão o sustentava, e a sua metamorfose tem efeito. Conforme as suas abstrações em hipóteses do que ele seria, ou poderia ter sido caso o fardo de ser o que ele realmente é não lhe fizesse cobranças, eis o desamparo à procura de âncoras:

Pus-me a correr tonto com a fumaceira tóxica em volta, à procura do que já nem sabia, à procura do meu irmão eu reconheço eu reconheço, de um sinal que me conduzisse até o seu paradeiro para que eu pudesse salvá-lo sei lá de sua própria existência e assim pudesse salvar a mim mesmo recuperando a minha honra, se bem que até ali nada indicava com firmeza que eu perdera alguma coisa como a honra (NOLL, 1994, p. 58).

Cabe aqui citar as definições sobre sujeitos pós-modernos de Jonathan Culler (1999), que também se aproximam das características do narrador de $A$ céu aberto (1996):

O sujeito é um ator ou agente, uma subjetividade livre que faz coisas, como no 'sujeito de uma sentença'. Mas um sujeito também é sujeitado, determinado, 'o leal súdito de sua Majestade, a Rainha', ou o 'sujeito de um experimento'. A teoria se inclina a argumentar que ser um sujeito é estar sujeitado a vários regimes (psicossocial, sexual, linguístico) (CULLER, 1999, p. 108).

Segundo o autor, a sensação de equívoco é a principal pauta dos sujeitos pósmoderno: são ambivalentes, contraditórios e insatisfeitos, e as narrativas acabam por entrar em consonância com esses aspectos. Dessa forma, um elemento alimenta o outro, 
no sentido de que a essência efêmera do sujeito encaminha uma linguagem fluída, e a relação entre sujeito e narrativa se firma. De acordo com Hartmann (2011), o sujeito que percorre as narrativas do Noll se apresenta múltiplo porque está em crise em não ter conhecimento sobre si mesmo: é um camaleão que, pela linguagem, se mostra como detentor de múltiplas faces, plácido, paternal, irônico, lascivo, desesperado (HARTMANN, 2011, p. 74).

A trajetória do protagonista ainda é afetada pela transformação do irmão em fêmea, em esposa, em um duplo ser que cumpre ambos os papéis. Ainda que em tentativas de explicações lógicas, as identidades, nas narrativas de Noll, não beiram o fixo. Podemos compreender essa dupla existência como um paradoxo identitário, que funciona como uma fuga para o personagem, enquanto que, para o narradorprotagonista, não há exatamente um alarde sobre a transformação, como fica evidente no seguinte trecho:

Quando voltei o meu irmão estava diante do fogão aguardando a subida do leite que fervia. Ele vestia uma camisola azulada que Ihe vinha até os pés descalços. Transparente a camisola, e do outro lado do tecido fino havia o corpo de uma mulher. Precisarei romper com esse negócio de pensar nessa figura aí como meu irmão, falei dentro de mim (NOLL, 1996, p. 76).

A escrita convulsiva de Noll afronta o que seja convincente, linear ou verossimilhante em acontecimentos como este ao longo do romance, pois o protagonista, depois desse episódio de transformação e convivência com o irmão/fêmea, encontra sua mulher com outro - filho de Artur-, o acolhe como amante e tem sua esposa/irmão grávida, compartilhando paternidade. Ora, estamos, indiscutivelmente, em territórios afastados do que podemos considerar possível, e o protagonista ainda pondera: "seriam 
isso o que chamavam de loucura?" (NOLL, 1996, p. 122). De forma abrupta, somos transportados para anos depois, ausentes das figuras que pertenciam à vida do narrador. Ao mencionar as condições de seu casamento, o narrador evoca metáforas e imagens que se liquefazem:

e a água começou a rolar torrencialmente sobre nós e senti que ela podia se liquefazer junto com tudo, e mais líquido expulsei de mim para suas entranhas e nós gritávamos juntos, num solavanco me saiu outra gozada surpreendente como se viesse do cérebro de tão espremida, e molhados entramos no paiol e nos deixamos aquecer pelo bafo de uma vaca inesperada que de repente começou a nos lamber lamber lamber (NOLL, 1996, p. 126).

Com o fim próximo, há pouca estabilidade na narrativa e poucas recordações firmes. O narrador ainda se pergunta: "sou o mesmo homem ou tenho duas personalidades?" (NOLL, 1996, p. 137). O limbo de si é expandido. Em tentativa de fuga, o narrador embarca em navio de fugitivos. Estaria fugindo da guerra ou de sua própria confusão interior? Fugindo de sua própria fuga, o narrador escapa desse navio, com pensamentos suicidas: "Tomei um gole d'água e pensei que eu queria a dissipação completa sem deixar o mais insuficiente dos vestígios porque andava fatigado em extremo" (NOLL, 1996, p. 156). O romance se encerra de forma desorientada, em meio às incertezas do narrador: "eu estava com uma consciência extremada de como as coisas se mostravam no espaço mas ao mesmo tempo me sentia flutuar" (NOLL, 1996, p. 156). O campo a céu aberto revela a batalha existencial que nem sequer foi lutada.

\section{Considerações finais}


O romance $A$ céu aberto, coerente com a literatura nolleana como um todo, apresenta o artifício da linguagem em sua forma descontínua, com significantes isolados e desconectados, sem que haja uma sequência coerente ou verossimilhante dos fatos. Essa impossibilidade de organizar a experiência numa ordem temporal resulta numa estrutura que impede o personagem de reconhecer a sua identidade. Ao acompanharmos a trajetória de seu protagonista, foi possível averiguarmos a urgência de ancorar a si mesmo na diluição do eu, das relações e do mundo, em tentativas múltiplas de permanecer, além de uma identidade construída por fragmentos, o que se encaminha à metonímia do romance como um todo.

\section{Referências}

BAUMAN, Zygmunt. Identidade. Tradução Carlos Alberto Medeiros. Rio de Janeiro: J. Zahar, 2005.

CHIARELLI, Stefania (org.). Alguma prosa: ensaios sobre literatura brasileira contemporânea. Rio de Janeiro: 7Letras, 2007. p. 39-51.

CULLER, Jonathan. Teoria literária: uma introdução. Tradução Sandra Vasconcellos. São Paulo: Beca Produções Culturais, 1999.

ELIOT, Thomas Stearns. Poesia. Rio de Janeiro: Nova Fronteira, 2014.

FAULKNER, William. O som e a fúria. São Paulo: Cosac Naify, 2004.

HALL, Stuart. A identidade cultural na pós-modernidade. 11. ed. Tradução Tomaz Tadeu da Silva, Guacira Lopes Louro. Rio de Janeiro: DP\&A, 2006.

HARTMANN, Giuliano. Vida fluída e escrita perversa em João Gilberto Noll. 2011.

Dissertação (Mestrado em Letras) - Universidade Estadual de Maringá, Maringá, 2011.

NOLL, João Gilberto. A céu aberto. São Paulo: Companhia das Letras, 1996.

PINTO, Manuel da Costa. Literatura brasileira hoje. São Paulo: Publifolha, 2004. 
SANTOS, Claudete Daflon dos. Ser Escritor. In: DEALTRY, Giovanna; LEMOS, Masé;

SCHOLLHAMMER, Karl Erik. Fiç̧ão brasileira contemporânea. Rio de Janeiro: Civilização Brasileira, 2009.

TREECE, David. Prefácio. In: NOLL, João Gilberto. Romances e contos reunidos. São Paulo: Companhia das Letras, 1997. p. 7-16.

Recebido em 27 de janeiro de 2019.

Aceite em 18 de abril de 2019. 